\title{
OS BENEFÍCIOS DA NOTA FISCAL ELETRÔNICA
}

Alex de Oliveira Querubino, Irene Caires da Silva

Universidade do Oeste Paulista - UNOESTE, Especialização em MBA em Finanças e Controladoria, Presidente Prudente, SP. E-mail: alexquerubino@gmail.com, irene@unoeste.br

\section{RESUMO}

O objetivo principal deste artigo foi relatar o surgimento, proporção e benefícios trazidos pela Nota Fiscal Eletrônica (NF-e) para o Fisco, contribuinte vendedor, contribuinte comprador e Sociedade, deixado o modo antigo, que era emissão da Nota Fiscal manual, de lado. Os resultados mostram a contribuição significativamente em relação à agilidade na emissão da NF-e comparado a sistemática anterior. A metodologia utilizada para o presente artigo foi a revisão bibliográfica. Visto que baseado nos estudos do tema proposto, fica evidente que, o uso da NF-e lista inúmeros benefícios, desta forma fazendo com que os usuários tenham um diferencial em suas mãos.

Palavras-chave: Nota Fiscal Eletrônica, Benefícios, Empresas, Fisco.

\section{THE BENEFITS OF THE ELETRONIC INVOICE}

\begin{abstract}
The main objective of this article was to report the appearance, proportion and benefits brought by the Electronic Invoice (NF-e) for the Tax Authorities, the Taxpayer seller, the Buyer Taxpayer and the Company, leaving the ond mode, side. The results show the contribution significantly in relation to the agility in the emission of NF-e compared to the previous systematics. The methodology used for this article was the bibliographic review. Since based on the studies os the proposed theme, it becomes evident that, the use of NF-e lists numerous benefits, this way making users have a differential on their hands.
\end{abstract}

Keywords: Electronic Invoice, Benefits, Company, Treasury. 


\section{INTRODUÇÃO}

Antigamente os impostos eram pagos com base nas notas fiscais talonárias e após a implantação da (NF-e) isso teve praticamente fim.

A NF-e é um documento digital iniciado por meio de uma parceria entre o ENCAT (Encontro Nacional dos Administradores e Coordenadores Tributários Estaduais) e a Receita Federal do Brasil, vigorada desde o dia 15 de setembro de 2006, surgindo para substituir a nota fiscal impressa, modelos 1 e A1, com o objetivo de facilitar a arrecadação fiscal.

Azevedo e Mariano (2009), definem NF-e como um documento de existência exclusivamente digital, emitido e armazenado eletronicamente, com o intuito de documentar uma operação de circulação de mercadorias ou prestação de serviços, cuja validade jurídica é garantida pela assinatura digital do emitente e a Autorização de Uso fornecida pela administração tributária do domicílio do contribuinte.

A NF-e faz parte de um dos três subprojetos do SPED (Sistema Público de Escrituração Digital da Receita Federal), o qual também contempla a escrituração contábil e a escrituração fiscal.

As obrigações acessórias dos contribuintes são facilitadas pelo uso da NF-e e também é possível o acompanhamento pelo fisco em tempo real das operações comerciais, o que mostra a importância deste instrumento.

Assim o objetivo deste artigo foi estudar e evidenciar os benefícios que a NF-e possibilita ao contribuinte e as melhorias que os terão ao fazer uso desta ferramenta.

\section{METODOLOGIA}

O presente estudo aborda uma pesquisa qualitativa e exploratória. Segundo Gil (2002), a Pesquisa Exploratória, visa proporcionar maior familiaridade com o problema, de modo a torná-lo explícito ou a construir hipóteses.

A pesquisa qualitativa geralmente utiliza pessoas e suas criações, e precisam serem respeitados suas opiniões, crenças e valores. Todo trabalho de coleta de informação, deve observar que "[...] a fala dos sujeitos de pesquisa é reveladora de condições estruturais, de sistemas de valores, normas e símbolos [...]" (MINAYO, 2008) sendo deste modo rica em informações e reveladora.

Esta pesquisa foi realizada por meio da pesquisa bibliográfica de publicações especificas, como artigos, livros, além de anais compostos na área com a intenção de viabilizar fundamentos e conhecimentos com base no assunto, considerando conceitos de autores que tratam sobre a NF-e e seu benefício.

\section{RESULTADOS}

\section{OS BENEFÍCIOS DA NF-E}

\section{BENEFÍCIOS DA NF-E PARA O FISCO}

Com base no Portal da NF-e (2018) um dos benefícios atribuídos ao fisco foi a maior confiabilidade, pois a partir do momento em que passou a ser usada de forma eletrônica. Quando realizada de maneira manual gerava muitos erros ortográficos e que passavam despercebidos, já com o Emissor Gratuito da NF-e as falhas foram praticamente a zero, já que o próprio sistema acusa quando existe algo divergente ao que fato é exigido pelo Fisco. 


\section{BENEFÍCIOS DA NF-E PARA A SOCIEDADE}

Para a sociedade teve seu lado negativo, como por exemplo os trabalhos realizados pelas gráficas, que confeccionavam talões de notas fiscais, e com o surgimento da NF-e passou a cada vez mais a se tornar extinto do mercado, hoje ainda existe em alguns casos, algumas empresas que fazem uso do talonário, mas tudo indica que esse tipo de atividade está com seus dias contados.

Porem falando do benefício que ela traz para a sociedade, fica evidente que a redução de papeis em rodagem, posto em uso é grande, desta forma o favorecimento ao meio ambiente se torna claro. Mas a NF-e tem vantagens também em questão de empregos, muitas empresas foram iniciadas com proposito de proporcionar algum tipo de software para empresas para a emissão deste documento (Portal da NF-e, 2018).

\section{BENEFÍCIOS DA NF-E PARA O CONTRIBUINTE VENDEDOR}

Os números de benefícios são grandes, e o mais interessante para o contribuinte se da à redução de custos com impressão (Portal da NF-e, 2018), uma vez que ao confeccionar um talão se gastava $X$, hoje com o uso da NF-e houve quedas claras, já que em cada nota se usava 4 vias e com isso a despesa aumentava. Outro ponto positivo considerado benefício ao contribuinte é visto em questão ao armazenamento das notas, já que no modo antigo se arquivava em pastas físicas, hoje isso é feito de maneira digital em PDF ou XML. Houve facilitação também relacionado a extinção da AIDF (Autorização Para Impressão de Documentos Fiscais), uma vez que antes era necessário a emissão deste documento ao Fisco, para que fosse liberado a confecção dos talonários, sendo que com a nova estrutura de Notas Fiscais não há essa necessidade.

\section{BENEFÍCIOS DA NF-E PARA O CONTRIBUINTE COMPRADOR/REVENDEDOR}

A NF-e foi criada com o proposita de proporcionar benefícios a todos que as fossem fazer uso, e com o Comprador/Revendedor não foi diferente, pois a eliminação de digitação de Notas Fiscais na recepção das mercadorias veio para facilitar o modo de trabalho a quem estivessem encarregados da escrituração, sendo assim, consequentemente os números de erros diminuiriam.

\section{DISCUSSÃO}

Qualquer forma de emissão de nota fiscal, até mesmo a manual, fica sujeito ao aceite da Secretaria de Estado da Fazenda, com autorização sobre o domicílio fiscal da empresa interessada. Com a implantação da NF-e o retorno da Receita passou a ser muito mais eficaz.

Diante deste trabalho foi possível notar que a NF-e suscitou a facilidade no Feedback com a Receita Federal e também tornou evidente a pretensão do esclarecimento sobre os efeitos duvidosos que foram surgindo com o passar do tempo aos que fazem e faziam uso da NF-e

Em decorrência da dinâmica da contabilidade percebe-se que a nota fiscal eletrônica facilita bastante a função do profissional contábil, em função desse fato, ocorreu um avanço na contabilidade. 


\section{CONCLUSÃO}

Este estudo teve como proposito mostrar de uma forma clara e profunda os beneficios que a NF-e tem a aqueles que fazem seu uso, as vantagens que ela traz quando se é utilizada e tambem o lado negativo para os que indiretamente foram afetados com a inovaçao.

Desta forma, evidencía o alcance do objetivo esperado, diante da pesquisa bibiograafica para o detalhamento do retorno positivo e negativo que a NF-e traz e trará a aqueles que estao envolvidos diariamente com ela.

Por fim, observou-se que a notra fiscal eletronica trouxe um grande avanço para o profissional contábil diminuindo a sonegação fiscal e facilitando os orgãos fiscalizadores a realizarem o seu trabalho com mais precisão.

\section{REFERÊNCIAS}

AZEVEDO, O. R.; MARIANO, P. A. SPED: Sistemas Público de Escrituração Digital. - 2. Ed. São Paulo: IOB, 2009.

COLOMBO, A. A.; SARAIVA, A. W. P.; FERREIRA, A. Nota Fiscal Eletrônica: Transparência e avanço tributário. Revista cientifica eletrônica de ciências contábeis. ANO IV - Número 12 Outubro / 2008.

GIL, A. C. Como elaborar projetos de pesquisa. 4a. Ed. São Paulo: Atlas S/A, 2002.

MINAYO, M. C. S. O desafio do conhecimento. 11 ed. São Paulo: Hucitec, 2008.

Portal da Nota Fiscal Eletrônica. Disponível em: http://www.nfe.fazenda.gov.br/portal/sobreNFe.aspx?tipoConteudo=HaV+iXy7HdM=\#o5pq ecSMQJW=. 